Jurnal Instruksional, Volume 2, Nomor 1 |56

\title{
PENERAPAN PEMBELAJARAN DONGENG DALAM MEMBENTUK KARAKTER SISWA
}

\author{
Zulfitria, Happy Indira Dewi, Mutia Khanza \\ Magister Teknologi Pendidikan Universitas Muhammmadiyah Jakarta \\ zulfitria81@gmail.com
}

\begin{abstract}
Backgrounded by the current millennium era, that storytelling culture has been considered ancient and began to be abandoned. Fairy tales are stories that contain moral and social values that are useful for shaping the character of children. The strategy for forming children's characters is done by giving examples, habit of reading fairy tales, habit of listening to fairy tales, and creating supportive reading environments. The purpose of this study is the application of fairytale-based learning to the formation of student character in the millennium era to the maximum, enjoyable, and integrated with families and schools. The results of the study that the application of fairy tale learning is very helpful to teachers in conveying messages for the formation of better student character. This study uses qualitative approach in the form of observations, interviews and documentation. The conclusion of this study is that the application of story-based learning is very important used by teachers so that it can shape the character of students. The formation of children's characters can be done in the school learning environment and home or family environment.
\end{abstract}

Keywords: fairy tales, characters, students

\begin{abstract}
Abstrak
Dilatarbelakangi oleh era millenium sekarang ini, bahwa budaya mendongeng telah dianggap kuno dan mulai ditinggalkan. Dongeng merupakan cerita yang mengandung nilai-nilai moral dan sosial yang berguna untuk membentuk karakter anak. Strategi pembentukan karakter anak dilakukan dengan pemberian contoh, pembiasaan membaca dongeng, pembiasaan mendengarkan dongeng, dan penciptaan lingkungan baca yang mendukung. Tujuan penelitian ini adalah penerapan pembelajaran berbasis dongeng untuk pembentukan karakter siswa di era millennium secara maksimal, menyenangkan, dan terintegrasi dengan keluarga dan sekolah. Hasil penelitian menunjukan bahwa penerapan pembelajaran dongeng sangat membantu guru dalam menyampaikan pesan untuk pembentukan karakter siswa yang lebih baik. Penelitian ini menggunakan pendekatan kualitatif berupa pengamatan, wawancara dan dokumentasi. Kesimpulan dari penelitian ini adalah bahwa penerapan pembelajaran berbasis mendongeng sangat penting digunakan guru sehingga dapat membentuk karakter siswa. Pembentukan karakter anak dapat dilakukan di lingkungan pembelajaran sekolah dan lingkungan rumah atau keluarga.
\end{abstract}

Kata kunci: dongeng, karakter, siswa

\section{PENDAHULUAN}

Kebiasaan masyarakat Indonesia dalam membaca dan menulis masih terbilang sangat rendah. Rendahnya minat baca masyarakat Indonesia ini makin menyebabkan kualitas dan mutu pendidikan di Indonesia juga hanya jalan di tempat (stagnan) dan cenderung mundur. Berdasarkan beberapa penelitian, penyebab rendahnya budaya baca ini karena masyarakat Indonesia lebih suka 
menonton televisi (TV), mendengarkan radio, dan bergelut pada dunia maya (internet dan media sosial) dibandingkan membaca buku.

Membaca merupakan jendela dunia. Membaca sangat penting dilakukan bagi orang yang suka mendongeng. Dongeng adalah cerita yang tidak benar-benar terjadi atau cerita karya imajinasi pengarang. Salah satu unsur intrinsik yang ada dalam dongeng adalah memiliki amanat atau pesan moral. Oleh karena itu, dongeng bisa dijadikan sebagai media untuk membentuk karakter anak karena memiliki nilai budi pekerti yang bisa dipelajari oleh anak (Pusat Bahasa, 2013).

Di era millennium ini, aktivitas mendongeng sudah jarang dilakukan orangtua terhadap anak-anak mereka. Selain itu anak lebih senang bermain games atapun HP dibandingkan membaca maupun mendengarkan cerita/dongeng. Di era digital seperti sekarang ini, dua pertiga dari orangtua dan kakek-nenek merasa bahwa teknologi modern sudah menghilangkan tradisi mendongeng (Kartikawati, 2012). Jika kejadian ini terus berlanjut, maka anak-anak akan jauh dari akhlak, moral, dan etika dengan hilangnya karakter anak Indonesia.

Undang-undang No. 20 tahun 2003 tentang Sistem Pendidikan Nasional menyatakan bahwa "Pendidikan nasional berfungsi mengembangkan kemampuan dan membentuk watak serta peradaban bangsa yang bermartabat dalam rangka mencerdaskan kehidupan bangsa, bertujuan untuk mengembangkan potensi peserta didik agar menjadi manusia yang beriman dan bertakwa kepada Tuhan Yang Maha Esa, berakhlak mulia, sehat, berilmu, cakap, kreatif, mandiri, dan menjadi warga negara yang demokratis serta bertanggung jawab." (Depdiknas, 2003). Pembangunan karakter sudah menjadi amanat dalam pendidikan dan menjadi kewajiban bersama untuk mewujudkan Indonesia yang berakhlak, bermoral, dan beretika (Soelistyarini, 2011).
Rendahnya minat baca pada anak belum ditangani sepenuhnya oleh keluarga, sekolah, masyarakat dan negara. Jika ini terus berlanjut maka bangsa ini akan merugi, karena anak-anak yang seharusnya menjadi garda terdepan untuk menghadapi globalisasi ditingkat ASEAN dan dunia. Oleh karena itu penelitian dengan judul Penerapan Model Pembelajaran berbasis dongeng untuk pembentukan karakter siswa di era millennium dipandang penting untuk dilaksanakan.

Penelitian ini berfokus pada bagaimana penerapan model pembelajaran berbasis dongeng yang dapat membentuk karakter siswa. Tujuan penelitian untuk menerapkan suatu model pembelajaran berbasis dongeng yang dapat membentuk karakter untuk siswa di era millennium secara maksimal, menyenangkan, dan terintegrasi dengan keluarga dan sekolah.

\section{KAJIAN LITERATUR}

\section{Pembentukan karakter pada siswa}

Dunia pendidikan harus mampu menjawab tantangan saat ini. Guru dituntut berkreasi dengan memanfaatkan kecanggihan teknologi sebagai sumber belajar, media belajar, dan proses kegiatan belajar-mengajar. Guru era millenial harus melek Informasi Teknologi. Tidak ada alasan masalah guru muda atau tua, semuanya mempunyai tanggungjawab yang sama dalam mencerdaskan kehidupan bangsa sesuai amanat UUD 1945. Era millenial bukan menjadi suatu hambatan, namun bagaimana guru menyikapi era millenial ini menjadi tantangan ke arah kemajuan pendidikan. Upaya menanamkan nilai-nilai karakter pada anak di era millenial bisa dilakukan dalam pendidikan karakter. Pendidikan karakter merupakan pendidikan yang mengajarkan hakikat dalam ketiga ranah cipta, rasa, dan karsa mendukung perkembangan sosial, emosional, dan etis siswa (Isbell etc: 2014). 
Menurut Mulyasa (2012), pendidikan karakter dapat dilakukan dengan berbagai model, yaitu model pembiasaan dan keteladanan, pembinaan disiplin, hadiah dan hukuman, pembelajaran kontekstual, bermain peran, dan pembelajaran partisipatif. Dalam rangka memperkuat pelaksanaan pendidikan karakter, ada 18 nilai-nilai dalam pengembangan pendidikan budaya dan karakter bangsa yang dibuat oleh Kementrian Pendidikan. 18 nilai-nilai dalam Pendidikan karakter tersebut adalah:1) Religius; 2) Jujur; 3) Toleransi;4) Disiplin; 5) Kerja Keras; 6) Kreatif; 7) Mandiri; 8) Demokratis; 9) Rasa Ingin Tahu; 10) Semangat Kebangsaan; 11) Cinta Tanah Air; 12) Menghargai Prestasi; 13) Bersahabat/Komunikatif ; 14) Cinta Damai;15) Gemar Membaca; 16) Peduli Lingkungan;17) Peduli Sosial; dan18) Tanggung Jawab. Maka pentingnya pendidikan karakter sejatinya memberikan motivasi serta pencerahan bagi pemerintah, para pendidik, insan akademik serta stakeholder Pendidikan pada umumnya untuk segera sadar dan bangkit berupaya mencari solusi agar pendidikan karakter ini dapat diimplementasikan dengan segera di sekolah maupun rumah.

Pendidikan karakter bukanlah berupa materi yang hanya bisa dicatat dan dihafalkan serta tidak dapat dievaluasi dalam jangka waktu yang pendek, tetapi merupakan sebuah pembelajaran yang teraplikasi dalam semua kegiatan siswa baik di sekolah, lingkungan masyarakat dan di lingkungan rumah melalui proses pembiasaan, keteladanan, dan dilakukan secara berkesinambungan. Oleh karena itu keberhasilan pendidikan karakter ini menjadi tanggung jawab bersama antara guru, masyarakat dan orangtua.

\section{Model pembelajaran berbasis dongeng}

1. Sejak zaman dahulu dongeng sudah dikenal oleh nenek moyang kita. Dongeng dijadikan sebagai media dalam menanamkan nilai-nilai sosial maupun nilai kemanusiaan. Dongeng di luar negeri biasa disebut dengan sebutan folklore, merupakan cerita rakyat yang asalnya adalah sebuah kisah yang dituturkan dari mulut ke mulut dengan harapan bahwa sang anak bisa memetik nilai-nilai kebajikan dari cerita itu (Nurhadi dkk, 2010). Tetapi saat ini, seiring dengan perkembangan teknologi digital yang pesat, anak-anak milenial zaman sekarang memandang dongeng sebagai sesuatu yang kuno.

2. Dongeng berpotensi memberikan sumbangsih besar bagi anak untuk memiliki jati diri yang jelas pribadi yang berkarakter. Dongeng dapat digunakan sebagai sarana mewariskan nilai-nilai luhur kepribadian, secara umum dongeng dapat membantu anak menjalani masa tumbuh kembangnya. Anak-anak dapat memahami pola drama kehidupan melalui tokoh dongeng. Melalui dongeng, anak-anak akan terlibat dalam alur cerita. Dalam hal ini, anak-anak menumbuhkembangkan intelektualitasnya.

3. Model pebelajaran berbasis dongeng dapat dijadikan sebagai media pembentuk kepribadian dan moralitas anak usia dini, melalui metote dongeng akan memberikan pengalaman belajar bagi anak usia dini. Metode dongeng memiliki sejumlah aspek yang diperlukan dalam perkembangan kejiwaan anak, memberi wadah bagi anak untuk belajar berbagai emosi dan perasaan dan belajar nilai-nilai moral. Anak akan belajar pada pengalamanpengalaman sang tokoh dalam dongeng, setelah itu memilah mana yang dapat dijadikan panutan olehnya sehingga membentuknya menjadi moralitas yang dipegang sampai dewasa. Dongeng adalah cerita rekaan, khayal yang dianggap tidak benar-benar terjadi. Terdapat 
beberapa aspek didalamnya yaitu aspek intelektual, aspek kepekaan, kehalusan budi, emosi, seni, fantasi dan imajinasi, tidak hanya mengutamakan otak kiri, tapi juga otak kanan (Asfandiyar, 2010).

4. Dilihat dari isinya dongeng dibedakan menjadi lima macam yaitu: (1) Dongeng yang lucu Contoh: Dongeng Abu Nawas; (2) Fabel, fabel merupakan cerita pendek atau dongeng yang memberikan pendidikan moral yang menggunakan binatang sebagai tokohnya. Contoh: Dongeng kancil dan harimau; (3) Legenda, adalah: "Cerita yang isinya tentang asal-usul suatu daerah". Contoh: Asal mula Danau Toba; (4) Sage, yaitu dongeng yang mengandung unsur sejarah. Contoh: Panji semiring; (5) Mite, sebagai: "dongeng yang berhubungan dengan kepercayaan masyarakat, Contoh: Nyai Loro Kidul (Pankin, 2014).

5. Dongeng merupakan salah satu cara yang efektif untuk mengembangkan aspek-aspek kognitif (pengetahuan), afektif (perasaan), sosial, dan aspek kognitif (penghayatan) anak-anak. Dongeng memiliki potensi untuk memperkuat imajinasi, memanusiakan individu, meningkatkan impati dan pemahaman, memperkuat nilai dan etika, dan merangsang proses pemikiran kritis dan kreatif. Bagi anak-anak, duduk manis menyimak penjelasan dan nasehat merupakan sesuatu yang tidak menyenangkan. Sebaliknya, duduk berlama-lama menyimak cerita atau dongeng adalah aktivitas yang mengasyikkan. (Musfiroh, 2010).

6. Indonesia adalah negara yang kaya akan dongeng, khususnya dongeng untuk anak-anak. Masing-masing wilayah di Indonesia memiliki koleksi dongeng yang memanfaatkan potensi alam sekitar, supaya karakter anak dapat lebih terbangun. Hal ini disebabkan oleh kemasan dongeng yang merupakan perpaduan antara unsur hiburan dengan pendidikan dapat membentuk karakter pada anak era millennium.

\section{METODE PENELITIAN}

Penelitian dilaksanakan di Bogor. Responden penelitian adalah semua siswa di TK HIAMA kids beralamat di Vila Nusa 3 Blok KE 2 No.2 Bojong Kulur Gunung Putri-Bogor. Waktu pelaksanaan penelitian adalah Maret-Juli 2020.

Metode penelitian yang digunakan adalah metode penelitian kualitatif deskriptif yang bertujuan menyajikan realitas sosial dan tidak bermaksud menguji hipotesis (Suradika: 2000:13), dimulai dengan pengambilan data berupa pengamatan, observasi dan dokumentasi

\section{HASIL DAN PEMBAHASAN}

Pada hari pertama peneliti mendatangi TK Hiama kids pada hari Senin 2 Maret 2020 yang terletak di dalam perumahan berada dipinggir jalan, TK HIAMA tidak terlalu besar. TK HIAMA Kids beralamat Vila Nusa 3 Blok KE 2 No.2 Bojong Kulur Gunung Putri-Bogor. TK ini memulai aktivitasnya dari pukul $07.30-10.00$. Untuk TK B dimulai pukul 07.30 - 10.00 karena awal masuk siswa memulai belajar membaca iqro dan hafalan surat pendek. Untuk pukul 08.00-10.00 untuk level TK A dan Play Group (PG). Pukul 08.00 semua siswa berkumpul di halaman untuk berbaris, membaca tiga surat dan doa belajar, kemudian mereka masuk ke kelasnya masing-masing. Siswa PG berjumlah 4 Siswa. TK A berjumlah 5 Siswa dan Siswa TK B berjumlah 10 Siswa.

Visi TK HIAMA kids adalah Menciptakan generasi Qur'ani yang cerdas, kreatif, inovatif, dan professional dalam menghadapi tantangan zaman. Adapun Misi dari TK HIAMA kids adalah: 
1) Mengimplementasikan nilai-nilai Islam ke dalam lingkungan pembelajar.

2) Mengasah dan mengoptimalkan potensi siswa untuk mencapai Multi Intelegensi

3) Menciptakan kreativitas siswa sehingga menjadi asset bangsa yang bermanfaat.

Beranjak dari pemikiran inilah TK HIAMA kid menggunakan metode active learning dengan pembelajaran terpadu dan tuntas, dan suasana belajar yang PAKEM (Proses, Aktif, Komunikatif, Kreatif, Efektif, dan Menyenangkan).

Pada penelitian hari kedua, Selasa 3 Maret 2020 peneliti mewawancarai Informan dalam penelitian ini yaitu guru yang terlibat langsung dalam penelitian ini adalah guru wali kelas bu L. Beliau mengajar dari tahun 2017 sampai sekarang. Ibu L sangat sayang siswanya terlihat dari upaya mengelus punggung siswanya yang di dekat beliau, sabar, dan selalu ceria ketika mengajar. Guru dapat menumbuhkan semangat siswa melalui hal kecil yang ia ceritakan di sela-sela belajar mengajar.

Ibu L selaku wali kelas mengatakan bahwa kegiatan mendongeng ini telah beliau lakukan kurang lebih selama dua tahun. Ibu Lisnawati sering mendongeng berbagai macam cerita terutama yang memiliki nilai positif yang dapat dicontoh oleh siswa. Dalam melakukan metode ini ibu L menggunakan media buku cerita, boneka tanggan atau pun hanya menggunakan mimik wajah. Siswa menyambut kegiatan ini dengan penuh semangat dan sedikit demi sedikit membawa pengaruh yang baik untuk siswa. Melalui metode ini guru menjelaskan banyak perubahan karakter siswa yang awalnya tidak baik menjadi baik, misalnya siswa tidak lagi berteriak di dalam kelas, siswa selalu mengucapkan terima kasih jika diberi sesuatu, siswa meminta tolong jika membutuhkan bantuan dan siswa karakternya menjadi lebih sopan.

Pertemuan hari ketiga Hari Rabu tanggal 4 Maret 2020, peneliti melihat siswa sudah mulai baris-berbaris pada pukul 08.00 di depan kelas sambil membaca surah $\mathrm{Al}$
Fatihah dan doa belajar, setelah itu anak masuk satu persatu ke kelas sambil diperiksa kukunya, lalu anak dikondisikan untuk duduk rapi di bangkunya masing-masing. Guru mengucapkan salam dan menyapa anak-anak, lalu mengabsen kehadiran anak, kemudian murojaah sebelum mulai pembelajaran dengan membaca surat An Nass, Al Falaq dan Al Ikhlas bersama-sama sebelum melakukan kegiatan. Setelah selesai membaca doa, guru menginformasikan mengenai kegiatan yang akan dilakukan. Guru mengajak anak-anak bercakap-cakap tentang apa itu dongeng dan menanyakan pernahkah orang tua mereka membacakan dongeng sebelum tidur menggunakan media buku cerita yang bergambar.

Setelah selesai bercakap-cakap tentang gambar cerita, kemudian guru membaca isi cerita dalam buku bergambar secara berurutan, anak ditugaskan untuk mendengarkan cerita yang sedang dibacakan, siswa fokus hanya kepada guru tidak berbicara ataupun bercanda Kemudia setelah selesai membacakan cerita, guru lalu mengadakan tanya jawab dari cerita yang baru dibacakan. Selanjutnya anak diberi kesempatan untuk menceritakan kembali cerita/dongeng secara sederhana. Setelah selesai menyampaikan materi, guru menanyakan kembali tentang cerita menggunakan gambar yang disampaikan guru, lalu guru menugaskan kepada anak agar menyebutkan sifa-sifat tokoh yang ada pada cerita tersebut. Kemudian anak diminta tanggapannya apakah senang atau tidak perasaannya menerima materi cerita gambar yang telah disampaikan. Pukul 09.00 WIB waktunya anak istirahat, anak dikondisikan untuk duduk rapi dan bersama-sama membaca doa sebelum makan, kemudian mencuci tangan sebelum makan dan sesudah makan. Setelah selesai makan, anak bermain-main di luar kelas. Pukul 09.30 WIB waktunya anak masuk kembali dan anak dikondisikan untuk duduk rapi dan membaca doa setelah makan. Kemudian anak ditugaskan untuk mengingat kembali cerita yang telah disampaikan dalam cerita tersebut. Pukul 10.00 WIB waktunya pulang, anak dikondisikan untuk duduk rapi dan berdoa 
sebelum pulang, lalu mengucapkan salam kemudian anak bernyanyi-nyanyi. Setelah selesai, anak pulang bersama-sama.

Pada penelitian hari keempat, Kamis tanggal 5 Maret 2018 pukul $08.00 \mathrm{~s} / \mathrm{d} 10.00$ WIB, peneliti mengamati guru yang sedang merapikan para siswa ketika melaksanakan kegiatan baris-berbaris di depan kelas sambil membaca suarat Al Fatihah dan doa belajar, setelah itu anak masuk satu persatu ke kelas sambil diperiksa kukunya, lalu anak dikondisikan untuk duduk rapi di bangkunya masing-masing. Peneliti mengamati guru mengucapkan salam dan menyapa anak-anak, lalu mengabsen kehadiran anak, kemudian mengulang pelajaran yang sudah dihafalkan sebelum memulai pembelajaran dengan membaca surat An Nass, Al Falaq dan Al Ikhlas bersama-sama. Setelah selesai membaca surah tersebut, guru menanyakan tentang kegiatan yang dilakukan pada pertemuan sebelumnya dengan melakukan tanya jawab seputar cerita menggunakan gambar yang kemarin diberikan. Kemudian $\mathrm{Bu} \mathrm{L}$ menginformasikan tentang kegiatan yang akan dilakukan seperti kemaren bu guru akan membacakan dongeng dari sebuah buku cerita. Setelah selesai membacakan dongeng, kemudian siswa diberi kesempatan untuk menceritakan Kembali cerita dongeng yang tadi bu guru dongengkan. $\mathrm{Bu}$ guru menanyakan kembali tentang siapa saja tokoh dongeng yang diceritakan, kemudian siswa diminta tanggapannya apakah senang atau tidak perasaannya mengengar dongeng dari ibu guru tadi. Hampir semua siswa menjawab senang sekali.

Pukul 09.00 WIB waktunya anak istirahat, anak dikondisikan untuk duduk rapi dan bersama-sama membaca doa sebelum makan, emudian mencuci tangan sebelum makan dan sesudah makan. Setelah selesai makan, anak bermain-main di luar kelas. Pukul 09.30 WIB waktunya anak masuk kembali dan anak dikondisikan untuk duduk rapi, dan membaca doa setelah makan. Kemudian anak ditugaskan untuk mengingat kembali dongeng yang telah disampaikan dalam cerita tersebut. Pukul 10.00 WIB waktunya pulang, anak dikondisikan untuk duduk rapi dan berdoa sebelum pulang, lalu mengucapkan salam kemudian anak bernyanyi-nyanyi. Setelah selesai, anak pulang bersama-sama.

Penelitian hari kelima Jumat 6 Maret 2020 peneliti wawancarai 10 siswa HIAMA kids kelas B orang yaitu Iz, Df, Kl, Kh, Yd, $\mathrm{Ab}, \mathrm{Az}, \mathrm{Kn}, \mathrm{Ai}$ dan An. Ada beberapa informan dari siswa yang ditanyakan oleh peneliti yaitu: Informan Iz adalah anak Perempuan berusia 5,5 tahun ia merupakan siswa yang aktif, cerdas dan ceria. Informan ke dua Df Anak laki-laki berusia 6 tahun tidak bisa diam, termasuk anak yang super aktif dalam pembelajaran. Informan ketiga $\mathrm{Az}$ anak Laki-laki 6 tahun anaknya pendiam dan pemalu. Informan ke empat Yd anak Laki-laki berusia 5 tahun senang mengambar dan pendiam. Informan kelima Ai Anak perempuan 6 tahun anaknya aktif dan ceria selalu tersenyum. Kh anak perempuan usia 5.5 tahun aktif dan bersemangat jika ditanya bu guru. Peneliti bertanya mengapa sekolah di HIAMA kids? Kh menjawab karena dekat rumahnya, rumahnya Kh sebelah TK Hiama kids. Sedangkan Iz dan Ai menjawab karena banyak temen di sini. Ternyata mereka bertetangga. Df, Az dan Yd menjawab karena di sini ibu gurunya baik.

Dari hasil wawancara siswa HIAMA kids sangat senang dengan dongeng yang dibacakan oleh ibu guru, dari dongeng yang di ceritakan guru, siswa memiliki tokoh-tokoh favorit yang menjadi idola mereka. Mereka jadi mengetahui jika kita mempunyai sikap yang tidak baik maka kita tidak punya teman dan jika kita mempunyai sikap yang baik kita akan disayang oleh teman, bu guru, orang tua dan yang pasti Allah akan sayang kepada mereka.

Pada hari selanjutnya Senin 9 Maret 2020 peneliti bertanya kepada orang tua murid yaitu mamahnya $\mathrm{Kh}$, beliau mengatakan bahwa banyak sekali perubahan sikap dan perilaku Kh selama bersekolah di HIAMA kids, salah satunya Kh lebih tenang sikapnya, dulu Kh sering berteriak teriak, sejak sekolah sikap berteriaknya mulai berkurang karena Kh menceritakan bahwa anak yang suka berteriak 
temannya setan, Allah tidak senang anak yang berteriak karena itu tidak baik. Jika mau bicaralah dengan baik cerita mamahnya Kh. Ternya Kh senang jika bu guru sedang mendongeng si kancil dan kura kura serta cerita si penyu. Kh suka bercerita lagi ketika pulang sekolah. Bu Lisna punya boneka kurakura $\mathrm{n}$ kelinci warna pink, Kh sampai minta mamahnya untuk belikan juga, dengan tersenyum mamah Kh bercerita.

Rata-rata siswa sudah mampu menceritakan kembali isi dongeng secara sederhana, yaitu:

a) Mendengarkan dongeng dengan seksama;

b) Menceritakan kembali dongeng ketika disuruh oleh ibu guru

c) Menyebutkan tokoh-tokoh yang ada dalam dongeng tersebut;

d) Anak dapat mengungkapkan perasaannya tentang isi cerita;

e) Menyebutkan sifat-sifat tokoh yang ada pada cerita yang didengarnya;

f) Bisa membedakan karakter sifat dalam tokoh dongeng seperti: nakal, pelit, baik hati, berani, pemalu, pintar dan lain sebagianya;

g) Siswa dapat mengetahui karakter mana yang harus di contoh dan mana yang tidak patut di contoh

\section{KESIMPULAN}

1. Dengan menggunakan media boneka, guru lebih mudah mendongeng agar siswa mempunyai imajinasi dari visualisasi ketika guru sedang mendongeng. Hal ini dapat meningkatkan kemampuan anak dalam menerima isi dongeng yang telah disampaikan.

2. Peningkatan karakter siswa dapat terlihat dari perbedaan ketika awal masuk sekolah dan ketika sudah milai proses pembelajaran, khususnya karakater siswa berupa rasa ingin tahu. Kemajuan siswa berimajinasi dapat dilihat melalui perubahan tingkah lakunya yang tidak lagi berteriak di dalam kelas, mengucapkan terima kasih jika diberi sesuatu, meminta maaf jika berbuat salah, berbagi makanan kepada teman dan tidak merebut mainan ketika bermain bersama.

\section{REFERENSI}

Asfandiyar, Andi Yudha. 2010. Cara Pintar Mendongeng. Bandung: Mizan.

Depdiknas. Undang-Undang Republik Indonesia Nomor 20 Tahun 2003 Tentang Sistem Pendidikan Nasional.

Isbell, R., Sobol, J., Lindauer, L \& Lowrance. 2014. "The Effects of Storytelling and Story Reading on The Oral Language Complexity And Story Comprehension Of Young Children". Early childhood education journal.

Kartikawati, Eny. 2012. Hanya 33\% Orangtua yang Masih Sempat Mendongeng untuk Anak, (Online), http://wolipop.detik.com/read/2012/ 10/10/070850/2058848/857/hanya33-orangtua-yang-masih-sempatmendongeng-untuk-anak, diakses 1 Maret 2020.

Children". Early childhood education journal.

Mulyasa, E. 2012. Manajemen Pendidikan Karakter. Jakarta: Bumi Aksara. [9] Nurhadi, dkk. 2010. Bahasa Indonesia. Bandung: Erlangga

Musfiroh, Tadkirotun, 2010. Cerita Untuk Anak Usia Dini. Yogyakarta: Tiara Wacana,

Pusat Bahasa. 2013. Kamus Pelajar. Jakarta: Departemen Pendidikan Nasional. 
Parkin. 2014. Tales For Change: Using Storytelling To Develop People And Organization. Great Britain: Biddle's.

Soelistyrini, Dwi. 2011. Nilai Moral dalam Cerita Rakyat sebagai Sarana Pendidikan Budi Pekerti, (Online), $\mathrm{http} / / /$ kidemang.com/kbj5/index.ph $\mathrm{p} /$ makalah-komisi-b/1147-13-nilaimoral-dalam-cerita-rakyat-sebagaisarana-pendidikan-budi-pekerti

Suradika, Agus. 2000. Metode Penelitian Sosial. Jakarta: UMJ Press.

Zulfitria. Clara, Damayanti. 2018. Implementasi Metode Mendongeng Mengembangkan Potensi Siswa SD. Jurnal Holistika FIP UMJ. https://jurnal.umj.ac.id/index.php/h olistika/article/download/3094/27 